\title{
AS FINALIDADES DAS ÁREAS PÚBLICAS DE PRESIDENTE PRUDENTE NA
} MICRORREGIÃO 18

\author{
Valquíria Patricia Felix, Valquíria Pereira Bastos, Marcela do Carmo Vieira, Sibila Corral de Area \\ Leao Honda
}

Universidade do Oeste Paulista - UNOESTE. Curso de Arquitetura e Urbanismo, Presidente Prudente - SP. E-mail: sibila@unoeste.br

\section{RESUMO}

Com o processo de urbanização e o crescimento das cidades, os espaços públicos se tornaram mais necessários e de vital importância para o meio urbano, agregando qualidades ao ambiente e um caráter estético para o lugar (CUNHA, 2003). Entretanto, constata-se que muitas dessas áreas estão sendo ocupadas irregularmente para outras finalidades. Desta maneira, esta pesquisa, tem como objetivo levantar e analisar os loteamentos constituintes da microrregião 18 de Presidente Prudente, localizada na porção Sudeste da cidade e suas áreas públicas institucionais e de lazer, verificando sua real utilização, tendo em vista que inúmeras áreas foram doadas ou concedidas pelo poder público municipal ao longo dos últimos anos. As informações levantadas indicam que um grande número de áreas foram concedidas a terceiros, ferindo assim os preceitos legais, o que vem significar prejuízo urbanístico e a população dos bairros que ali residem.

Palavras-chave: ocupação irregular , áreas públicas, microrregião, legislação, alteração de função

\section{THE PURPOSES OF THE PUBLIC AREAS OF PRESIDENTE PRUDENTE MICROREGION 18}

\begin{abstract}
With the urbanization process and the cities development, the public spaces became more needed and acquired vital importance for the urban center, adding qualities for the environment and esthetic character for the place (CUNHA, 2003). However, we find that many of these public areas are being occupied irregularly for other goals. This way, the research, has as objective to set up and analyze allotments that constitute the microregion 18 of Presidente Prudente, localized at the southeast part of the city and its institucionals and recreationals public areas, verifying their real use, in view of that numerous areas were donated or granted from the city public power over the last years. The informations acquired show that a large number of these areas where granted by third parties, breaking the legal precepts, what comes to mean urban prejudice as well as prejudice for the population residing there.
\end{abstract}

Keywords: Illegal occupation, public areas, microregion, legislation, funtion alteration 


\section{INTRODUÇÃO}

A cidade de Presidente Prudente localiza-se no extremo oeste paulista (Figura 1), região denominada de Alta Sorocabana, tem como marco de sua fundação o dia 14 de setembro de 1917 e segundo o senso do IBGE (2010), residem na sede do município 203.375 habitantes. A Figura 1 a seguir representa a localização da cidade de Presidente Prudente no mapa do Estado de São Paulo, juntamente com a microrregião 18 trabalhada, sendo que esta área da cidade localiza-se à sudeste do centro urbano de Presidente Prudente.

A expansão urbana da cidade de Presidente Prudente, como se pode observar na figura a seguir e também apontada por Honda (2010, p. 73), "sempre ocorreu de forma mais dinâmica na direção sudoeste, como prolongamento da Vila Goulart", deixando grandes vazios urbanos, especialmente nas áreas da localizadas a Oeste da ferrovia que corta a cidade. Já a porção leste da ferrovia, onde se encontra a microrregião 18, o processo de expansão urbana foi menos acentuado, provavelmente devido aos terrenos com topografia mais acidentada localiza-se neste setor.

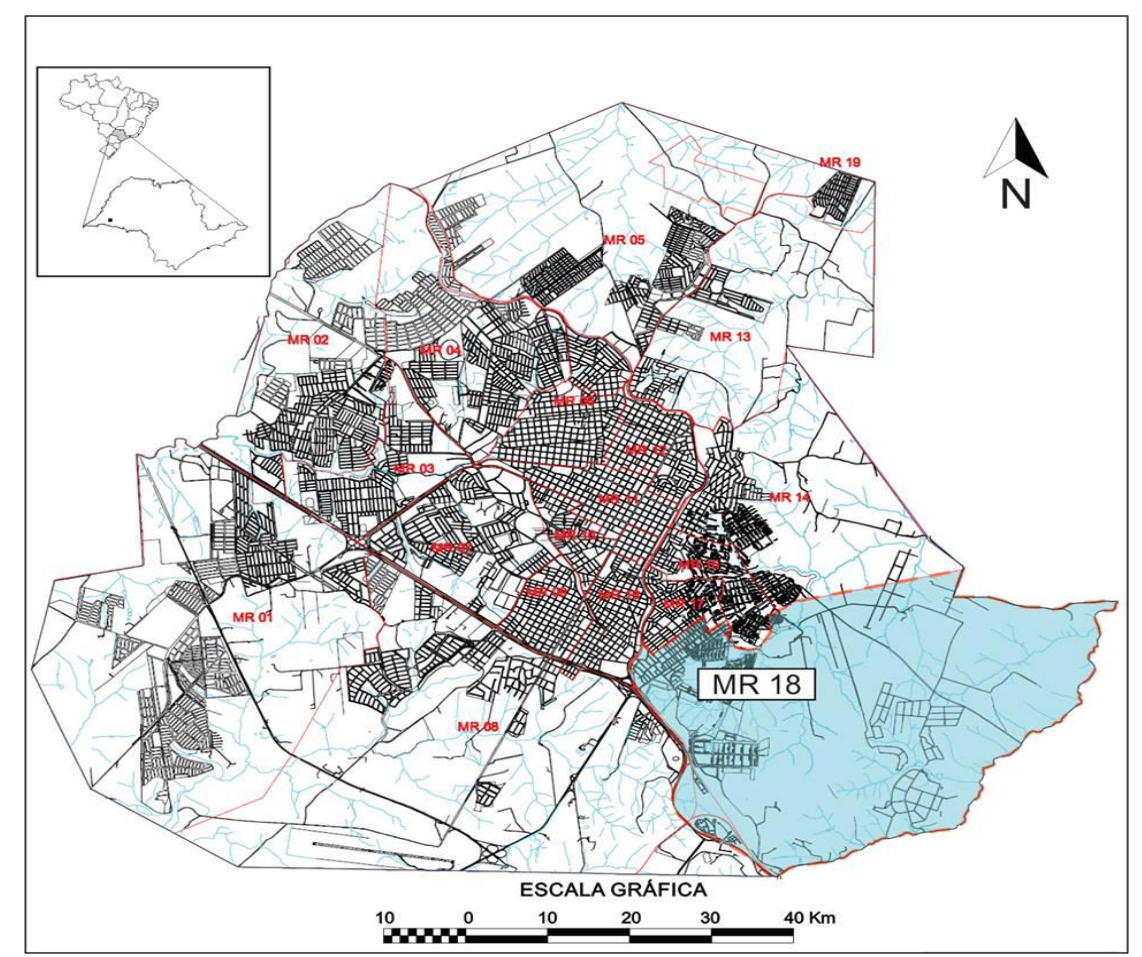

Figura 1. Localização da cidade de Presidente Prudente e a Microrregião-18 FONTE: autores, 2014

Nos parcelamentos de solo existentes antes e após a da Lei de Parcelamento (Lei n. 6.766 de 19 de dezembro 1979), as áreas/espaços públicos (verdes e institucionais) de Presidente Prudente, foram concedidas e doadas a terceiros, reduzindo assim as possibilidades do poder público 
municipal em atender as necessidades de instalação dos equipamentos urbanos e comunitários para a população prudentina.

Estas condições justificam o estudo das áreas publicas na microrregião-18, visando entender a lógica da redução de tais espaços e propor soluções bairro a bairros que atenda a um crescimento harmonioso com melhor qualidade de vida destinado a população.

\section{METODOLOGIA}

Realizar-se-á um levantamento bibliográfico buscando o aprofundamento acerca dos temas relacionados à pesquisa, levantamento de pesquisa documental, levantamentos físico territoriais urbanísticos das áreas livres públicas e áreas institucionais da cidade de Presidente Prudente - SP.

O levantamento bibliográfico será de base conceitual sobre os termos áreas livres públicas e áreas institucionais. Para a fase de pesquisa documental serão levantadas plantas dos loteamentos, leis e decretos disponíveis na pagina oficial da Prefeitura Municipal de Presidente Prudente existente na internet e o Inquérito Civil n. 323/11-6 do Ministério Público do Estado e São Paulo, aberto para investigar o assunto.

A revisão bibliográfica consistirá no levantamento de conceitos chaves ligados aos espaços livres e sobre leis que tratam do assunto, tanto no âmbito urbanístico quanto no ambiental. Serão levantadas informações referentes a estudos sobre o crescimento e a expansão da cidade. Também serão consultados, livros, trabalhos e artigos que versem sobre os aspectos relacionados a importância das área públicas no interior das cidades.

O levantamento físico territorial tem como objetivo verificar aspectos relativos ao uso e ocupação do solo, equipamentos e serviços, a localização e a conformidade dos usos aos quais foram destinadas.

Utilizando de técnicas de geoprocessamento e sensoriamento remoto, através do Programa Spring 5.2.3, sobre imagem de fotografias aéreas e imagem de satélite do Google Earth, mapear-se-á a área da microrregião 18, para se verificar a situação das áreas públicas existentes nas plantas dos loteamentos obtidas no site da PM de Pres. Prudente. Estas informações possibilitarão uma análise da ocupação das áreas públicas em cada loteamento da microrregião.

Após o levantamento da situação das áreas públicas dos loteamentos da microrregião será efetuado visita "in loco" para verificar a real destinação dada as área públicas. Para a realização da pesquisa será adaptada à metodologia que consiste na organização de Inventário e elaboração de diagnóstico urbanístico. 


\section{RESULTADOS}

A microrregião 18 se localiza na região sudeste de Presidente Prudente e é constituída por doze bairros. A maioria da população desses bairros possuem um baixo poder aquisitivo, com casas de um a dois pavimentos, a maioria ainda em fase de execução por falta de recursos. As áreas de lazer são geralmente compostas por Academia da Terceira Idade, praças com bancos e mesas de concreto, algumas quadras e vegetação. Nas áreas institucionais, postos de saúde e escolas são mais freqüentes.

Os bairros que compõe a microrregião 18 são o Jardim Planalto, Vila Aurélio, Vila Rotária Arch C. Klumph, Vila de Ramos Freitas, Jardim Cambuci e Conjunto do Cambuci, Jardim Paraiso, Jardim Nova Planaltina, Jardim Santa Mônica, Jardim Santana, Jardim São Bento e, por fim, o Conjunto Habitacional Parque José Rotta.

No bairro Nova Planaltina, a área institucional de escritura 920/83 foi doada em 1989 para a Prudenco para o programa de desfavelamento; entretanto, o bairro ficou sem nenhuma área pública voltada aos seus moradores. A área de lazer de escritura 918/83 não possui nenhum equipamento urbano para a comunidade, e se encontra apenas gramada. Ainda perto dessa área, uma via ultrapassa os limites da área de lazer, mostrando o desrespeito do município para com as necessidades da comunidade de baixa renda.

No Jardim Paraiso, toda a grande área de lazer do bairro (esc. 1350/91) sofreu alteração de função e destinou sua finalidade a uso de residências; ao que parece, a população não possui conhecimento a respeito da ocupação ilegal. A área institucional encontra-se ocupada pela Escola Municipal Professora Vilma Alvarez Gonçalves e a APP protegida por grades e com vegetação.

O Jardim Cambuci possui uma área institucional ocupada pelo CRAS (Centro de Referência de Assistência Social) e área de lazer composta por academia da terceira idade, parquinho e uma quadra. Uma parte da área de lazer foi doada para o CDHU em 1984 para ser implantado um Conjunto Habitacional através da lei 2382/82. Apesar de existir uma área de lazer, ela não atende a grande extensão do bairro pois é pequena e não fica no centro do loteamento.

No Jardim Santa Mônica, a escritura 1125/87 está destinada como área de lazer, entretanto está ocupada por uma residência. Ao lado, na área de proteção hídrica, um ferro velho se encontra no local. As duas propriedades ilegais aparentam ser ocupadas pela mesma pessoa, já que não há muro entre a casa e o ferro velho.

No Jardim São Bento a área da escritura 791/80 defende toda sua extensão como área de lazer, entretanto ela se encontra parcialmente loteada. Na outra parte da área de lazer foi constatada a ocupação da Praça Antonio R. Maia, onde está instalada campo de futebol, quiosque, 
bancos, e quadra coberta, não recomendado para a região, já que é uma Área de Proteção Ambiental, e deveria estar ocupada por equipamentos urbanos que não influencie a área de permeabilidade do local.

No Conjunto Habitacional Parque José Rotta, as escrituras 1849/11 e 1850/11 que definem como função um espaço para área verde e institucional estão parcialmente invadidas com uma construção em madeira.

No Jardim Planalto a área de lazer da esc. 107/73 está ocupada por playground e academia do idoso; encontra sem manutenção e seu aspecto é de total descaso do poder público e da comunidade de preservar e manter o espaço, com a finalidade de uso comum do povo. A área de preservação permanente teve parte ocupada por plantação de vegetais e hortaliças.

Os outros bairros da microrregião que não foram citados (Vila Aurélio, Jardim Santana, Vila Ramos de Freitas, Vila Rotária Arch C. Klumph e as áreas sem denominação) estão ocupados de acordo com a finalidade de suas respectivas áreas públicas.

\section{DISCUSSÃO}

É possível observar que a microrregião 18 enfrenta alguns problemas de alteração de finalidade de suas áreas públicas; bairros sem nenhuma área verde, áreas de lazer inteira ou parcialmente ocupadas por residências e falta de manutenção das praças comprovam a falta de fiscalização e o descaso com as áreas públicas que o município de Presidente Prudente tem com os bairros em questão.

Com o trabalho em campo foi possível observar melhor os problemas encontrados no Relatório de Levantamento das Áreas Públicas da Micro Região 18 (IC №333/2011) e entender que, apesar do adensamento de muitos dos bairros, ainda se encontra um grande vazio urbano na área trabalhada.

A Constituição da República Federativa do Brasil de 1988, entrega aos municípios a responsabilidade pelo desenvolvimento urbano e expansão territorial, e cabe ao mesmo dividir parcialmente áreas destinadas para benefício da população como um todo. Em Presidente Prudente na década de 90, áreas destinadas ao lazer foram entregues ao poder público local para outras finalidades; a partir de então ocorreu o desvio de função dos espaços de lazer e institucionais. A Lei Federal no 6.766/79 do parcelamento do solo refere-se aos espaços livres como domínio público, mas não define de quem é a obrigação de cuidar e manter esses espaços. 


\section{CONCLUSÃO}

Dessa maneira, não cabe somente à Prefeitura preservar os espaços públicos, já que também é dever da população prezar pelos espaços da comunidade. Com a falta de informação da comunidade e de planejamento urbano do município, as áreas públicas acabam sendo tomadas pelos cidadãos para uso pessoal, prejudicando-os.

O poder público poderia disponibilizar novos loteamentos no grande vazio urbano da microrregião, estimulando o crescimento da cidade para a região sudeste; o terreno acidentado gera maiores dificuldades para tal, mas é possível reverter a situação com a elaboração de projetos específicos para a topografia local.

\section{REFERÊNCIAS}

BENINI , Sandra Medina; MARTIN, Encarnita Salas. Decifrando as áreas verdes públicas [publicação on-line]. Disponível em: < http://revista.fct.unesp.br/index.php/formacao/article/viewFile/455/489> Acesso em: 24 jun. 2014.

BRASIL. Lei no 6.766, de 19 de dezembro de 1979.

KECK, Cleo; ALVES, Manoel; PEREIRA, Nixon. O processo de ocupação do espaço urbano, no contexto das políticas públicas, da cidade de Lábrea no estado do Amazonas: o caso da comunidade Beira Rio. [publicação on-line]. Disponível em: <http://www.convibra.com.br/upload/paper/2012/38/2012_38_4998.pdf> Acesso em: 24 jun. 2014.

LIMA, Valéria; AMORIM, Margarete. A importância das áreas verdes para a qualidade ambiental das cidades [publicação on-line]. $\quad$ Disponível em: http://revista.fct.unesp.br/index.php/formacao/article/viewFile/455/489> Acesso em: 24 jun. 2014.

PIOLI, Maria Sulema; ROSSIN, Antonio Carlos. O meio ambiente e a ocupação irregular do espaço urbano. [publicação on-line]. Disponível em: <http://www.rbciamb.com.br/images/online/03_artigo_6_artigos112.pdf> Acesso em: 24 jun. 2014.

Procuradoria Geral de Justiça - Centro de Apoio Operacional das Promotorias de Justiça de Urbanismo e Meio Ambiente - Área Regional de Presidente Prudente. Destinação de áreas públicas (Área Institucional e Área verde), para outras finalidades que não aquela prevista em Lei, na cidade de Presidente Prudente - SP. Parecer no 027-2009. Autos: IC №138/08. Interessado: Ministério Público do Estado de São Paulo. 